\title{
Living-in-history effect in the dating of important autobiographical memories
}

\author{
Azharul Islam ${ }^{1,2}$. Shamsul Haque ${ }^{1}$ (1) \\ Accepted: 4 October 2021 / Published online: 30 November 2021 \\ (c) The Psychonomic Society, Inc. 2021
}

\begin{abstract}
The tendency of a person to frequently use public (i.e., historical) events as temporal landmarks when dating personal memories is termed the living-in-history $(\mathrm{LiH})$ effect. We investigated the $\mathrm{LiH}$ effect in autobiographical memories of Bangladeshi older adults who lived through the 1960s Bengali nationalist movement and the 1971 Bangladesh War of Independence. 476 participants (mean age $=67.16$ years; $\mathrm{SD}=5.96$ years), including 62 independence war veterans, retrieved and dated three important memories from their life and completed two scales: (a) a transitional impact-of-war scale and (b) a generational identity scale. Results showed that nearly one-third of the total memories (32\%) were dated using public event references, demonstrating a LiH effect. However, this effect was twice as strong among veterans (58\%) than among nonveterans (28\%). The memory content analysis revealed that public event references were mostly used to date public memories (e.g., war and political struggle) and the memories with negative valence. Multivariate analyses showed that veteran identity, material changes due to war and participants' age significantly predicted the use of public event references to date one, two or three memories relative to no use of those references. The public memories that were personally significant and the extent participants experienced the material changes due to war mainly caused the $\mathrm{LiH}$ effect. We discuss the results considering current theories of autobiographical memory.
\end{abstract}

Keywords Autobiographical memory · Living-in-history effect · Transition theory · SMS · Generational identity · Bangladesh

\section{Introduction}

Autobiographical memory (AM) is a memory system whereby mental representations of past episodes are constructed by associating knowledge with different levels of abstraction. One crucial feature of AM is the construction of the timing or dates of the retrieved episodes. When constructing the event dates, people use temporal landmarks that are often transitional events (Brown, 1990; Brown \& Lee, 2010; Brown et al., 2009; Friedman, 1993; Shum, 1998; Thompson et al., 1996). The utility of a transition to be a

Shamsul Haque

shamsul@monash.edu

1 Department of Psychology, Jeffrey Cheah School of Medicine and Health Sciences, Monash University Malaysia, 47500 Bandar Sunway, Selangor Darul Ehsan, Malaysia

2 Department of Educational and Counselling Psychology, University of Dhaka, Dhaka, Bangladesh landmark event for dating AMs is suggested to be a function of its impact on the people. For example, war and natural disasters are events that often change people's livelihood in such a way that their life before and after becomes markedly different. Therefore, these events are expected to be used as landmark events more frequently than other events (Brown et al., 2012; Brown et al., 2009). Frequent references to such historical events when dating mundane personal memories is termed the living-in-history $(\mathrm{LiH})$ effect (Brown \& Lee, 2010). In this study, we investigated if the 1971 Bangladesh War of Independence, which changed the fabric of millions of Bengali people's daily lives and eventually altered their national identity, also acts as a landmark for dating AMs.

\section{Theories of autobiographical memory (AM)}

The Self-Memory System (SMS) theory, one of the frequently studied frameworks of AM construction and organisation (Conway \& Pleydell-Pearce, 2000), proposes that 
autobiographical knowledge is organised following a hierarchy with lifetime periods at the top of the hierarchy, general events in the middle, and event-specific knowledge at the bottom. Lifetime periods are the most abstract, more general knowledge defined by goals operating within roughly delineated temporal boundaries (e.g., when I was doing Ph.D. in Malaysia). General event knowledge arises during life periods that are more specific events unified by a common theme (e.g., writing my thesis). Event-specific knowledge refers to memories of events that occur at one specific point in time and are typically measured in units of seconds, minutes, or hours (e.g., I had a meeting with my supervisor on writing progress at a local restaurant as the campus was shut down for COVID-19). According to the SMS theory, the organisation and retrieval of AMs is the function of the working self that regulates current goals and conceptual self. To retrieve a memory, the working self creates a framework that guides the memory search towards goal-relevant past experiences within a time frame bounded by a general life period (Conway, 2005; Conway et al., 2004).

An alternative to the SMS, the Transition theory suggests that the content and organisation of AMs replicate the structure of daily life experiences, which are essentially repetitive (Brown, 2016). Following the operation of basic associative processes, co-occurring repetitive life events formed an interconnected event network resulting in an AM. A major life transition, however, terminates a large set of event components and replaces it with another set of event components. Transitions are period-binding synchronised events that bring large-scale change in everyday life. This change brings a new lifetime period. If a historical event brings such changes, it is called the historically defined autobiographical period (H-DAP). Transition theory holds that people experiencing major transitions use H-DAPs to date personal memories such as "it happened after the 1965 earthquake" (Brown et al., 2016). It has been suggested that significant transitions in life help structure AMs across the lifespan (Brown et al., 2012; Brown \& Lee, 2010; Brown et al., 2009).

Evidence for the LiH effect, operationalised as the percentage of memories dated in reference to public events, has been found mostly in historical events that had a marked impact on the population. For example, the $\mathrm{LiH}$ effect ranged from 17\% to $23.9 \%$ for the Bosnian Civil War (1992-1995), $5.5 \%$ to $26 \%$ for WWII (Bohn \& Habermas, 2016), 5.3\% for the Kosovo War, $13.70 \%$ to $26.62 \%$ for Lebanese Civil War, and $4.3 \%$ for the breakup of Yugoslavia (Brown \& Lee, 2010; Brown et al., 2009) (see Supplementary Table 1, Online Supplementary Material). Other historical/public events that produced significant $\mathrm{LiH}$ effects were the Chinese Cultural Revolutio (11.8-25.9\%; Gu et al., 2017), earthquake in Turkey (0.3-13.9\%; Brown et al., 2009), migration to Canada (15\%; Shi \& Brown, 2016), and Fall of Berlin
Wall (1.0-7.1\%; Camia et al., 2019). However, the $\mathrm{LiH}$ effect was less apparent in the region where the public events had less impact on the citizens. For example, the $\mathrm{LiH}$ effect for the Iraq/Afghan war among American samples ranged from $0.3 \%$ to $1.0 \%$ (Brown \& Lee, 2010; Brown et al., 2009). The collapse of the Soviet Union produced less than $1.0 \%$ LiH effect among Russian participants (Nourkova \& Brown, 2015).

The variation in the $\mathrm{LiH}$ effect across different studies was primarily attributed to the disparate impact the transitional events produced upon the individuals experiencing it (Brown, 2016). For example, Zebian and Brown (2014) observed marked variations in the $\mathrm{LiH}$ effect for the same historical event. Lebanese participants who were closer to the Lebanese civil war (thus assumed to be more affected) used significantly more public dating references $(26.6 \%)$ than those who lived very far from the event (13.7\%). Svob and colleagues developed the Transition Impact Scale (TIS) to capture the material and psychological changes that a collective transition brought about in civilians' lives (Svob et al., 2014). Gu et al. (2017) used TIS to assess the transitional impact of the Chinses Cultural Revolution (1966-1976) among the older Chinese participants. They found that participants who were forced to move from cities to rural areas (i.e., rusticated group) tend to experience more material but not psychological changes due to the revolution than those who remained in their regular households (i.e., non-rusticated group). The material change was related to the degree of the $\mathrm{LiH}$ effect.

Camia et al. (2019) administered TIS to the participants recruited from East Germany to assess the impact of the fall of the Berlin Wall. Their results showed that East Germans experienced significantly higher material change but less psychological change. However, neither change dimensions were related to the $\mathrm{LiH}$ effect's strength, thus failing to find support for the transitional impact hypothesis. Although the $\mathrm{LiH}$ effect was predominantly found for the negative events, Camia et al. (2019) observed that the fall of the Berlin Wall, a positive event, also elicits a moderate $\mathrm{LiH}$ effect in East Germans' dating protocols. However, there was no link between perceived changes in life due to the Fall of the Berlin Wall with the proportion of dating references related to this historical event. These results indicate that in addition to the factors operating at memory encoding, factors at retrieval might play a role in the individual differences in the $\mathrm{LiH}$ effect.

Ample research has shown an integral relationship between AM and self-identity (Conway et al., 2019; Conway et al., 2004; Ernst \& Rathbone, 2019). It is found that a special set of memories help build a particular identity. Holding that identity, in return, facilitates the recall of identity-relevant memories. This relationship could be useful to understand the memory organisation among participants 
who experienced a major collective transition during their formative years. Young people affected by collective transition share similar social, political, and economic consequences, which would likely help them form a distinct identity called the generational identity (Holmes \& Conway, 1999; Mannheim, 1952). The generational identity could be blended with personal identity for the individual experiencing transitional events (Dragojević, 2013). Hence, individual differences in the $\mathrm{LiH}$ effect might occur due to the individual differences in the magnitude of the identification with the transitional event.

\section{The present study}

We aimed to examine the factors related to encoding, retention, and retrieval of AMs to understand the $\mathrm{LiH}$ effect at a deeper level. In this study, besides the memory level data (i.e., AMs and dating protocols), we gathered participantlevel data likely to influence the encoding and retrieval of AMs. For instance, we assessed the impact of the liberation war on our participants using the TIS. The scores of TIS would be used as a metric of event impact, which indicates encoding properties. We also assessed the generational identity of our participants - a construct that is operative at the retrieval level.

Whereas Brown and colleagues (Brown et al., 2016; Brown, 2016; Brown et al., 2012; Brown \& Lee, 2010) examined the $\mathrm{LiH}$ effect for AMs elicited through word cues, we utilised the important memory method. We assumed that the LiH effect would be stronger in the dating of the most important AMs. A request for important memories activates a generative search resulting in a life period expected to contain the most significant life events (Crovitz \& Schiffman, 1974; Koppel \& Berntsen, 2019). These significant events often act like a script that is then used to organise personal memories. Berntsen and colleagues termed these culturally shared significant events cultural life script (Berntsen \& Rubin, 2002; Rubin \& Berntsen, 2003). Previous studies on participants who have witnessed historical events showed that historical events and cultural life scripts played a role in dating personal memories (Bohn \& Habermas, 2016; Camia et al., 2019). If a historical event produces an enduring change in one's life, the event will also likely be considered most important and activate many memories.

We had three specific objectives: First, to calculate the percentage of AMs that were dated in reference to the important public events; second, to see if veteran and nonveteran participants differed in terms of the usages of H-DAPs in dating their memories; and third, to examine the differential effects of participants' age, veteran and nonveteran identity, generational identity (GIS scores), and transitional impact of war (TIS scores) on using H-DAPs while dating their memories.

\section{Method}

\section{Participants}

Data were collected as part of a large study exploring the content and organisation of AMs shared by the Bangladesh independence war generation. For the current study, 550 older adults and elderly participants were recruited from ten districts (Dhaka, Netrokona, Tangail, Narayanganj, Barisal, Gazipur, Rajshahi, Potuakhali, Bogra and Cumilla) in Bangladesh via poster advertisements and snow-ball technique. Eighteen participants were excluded from initial cognitive screening (see Measures). Data from another 56 participants were incomplete, therefore excluded from the analysis. The final sample comprised 476 participants (29.41\% female). Participants' age ranged from 55 to 90 years, with a mean of 67.16 years (SD 5.96 years). Almost half of the participants had no formal schooling (45.59\%), $26 \%$ up to secondary level, and the remaining $26.36 \%$ had completed higher secondary or above degrees. All participants lived through the 1971 Bangladesh independence war when they were aged from 6 to 41 years, with a mean of 18.40 years (SD 5.97 years); they were war veterans $(n=62)$ and nonveteran men $(n=274)$ and nonveteran women $(n=140)$. The reason for our initial classification separating nonveteran men and nonveteran women is to make a comparison with war veterans who were all men. Veterans $(M=69.44, S D=4.95)$ were slightly older than nonveteran men $(M=66.97, S D=$ $5.95)$ and nonveteran women $(M=66.59, S D=6.43), F(2$, $473)=5.28, p<.01, \eta 2=.02$. However, nonveteran men and nonveteran women did not differ systematically in the main findings of this study; hence, those results were not reported further. Veterans and nonveterans were similar in their self-reported socioeconomic status, $\chi^{2}(2,476)=4.77$, $p=.092$, Cramer's V $=0.100$, but the veterans had a higher level of education (year of schooling) than their nonveterans counterparts, $\chi^{2}(3,476)=9.23, p<.05$, Cramer's V $=.139$.

\section{Measures}

\section{Screening for cognitive impairment}

As we recruited older participants, they could have some degree of cognitive impairment, which might influence their memory recall. Therefore, we screened them before data collection using the Short Portable Mental Status Questionnaire (SPMSQ, Pfeiffer, 1975), a ten-item tool to detect the degree of organic brain deficit among elderly participants. The SPMSQ has been found to be valid and reliable 
in differentiating demented from nondemented subjects (sensitivity and specificity were .74 and .91, Roccaforte et al., 1994). Each incorrect response to the SPMSQ item was scored 1 , and the correct response was scored 0 . Therefore, the total score could range from 0 (no errors) to 10 (all errors), in which a higher score indicated a higher cognitive impairment. Pfeiffer (1975) suggested the following indexes for Caucasian participants with at least some high school education: intact cognition ( $0-2$ errors), mild impairment (3-4 errors), moderate impairment (5-7 errors), and severe impairment (8-10 errors) in cognitive functioning. Considering the lower educational level of the present sample (e.g., many had no formal education), we considered up to five errors as mild cognitive impairment suggested by Pfeiffer (Pfeiffer, 1975). The current sample comprised of participants who scored five or less on the SPMSQ.

\section{Autobiographical memory}

We asked participants to recall three AMs from their life which they considered most important. For each AM, participants gave a short description so that they could easily recognise the reported memory later. After describing the memories, participants estimated their age at the time of each memory and the corresponding calendar year. These were the think-aloud dating protocols that we recorded and coded for further analysis.

\section{Generational identity}

We developed and validated a 12-item Generational Identity Scale (GIS-12) to assess generational identity for this sample (Islam \& Haque, 2021). The GIS-12 consists of two factors: identification with the generation (seven items, e.g., I identify myself with my generation) and awareness of the generational importance (five items, e.g., I think my generation is meaningful to many people) (Table 1).
Participants responded to each item on five-point Likert type scale (i.e., 'completely disagree' [1], 'disagree' [2], 'don't know' [3], 'agree' [4] and 'completely agree' [5]). Scores for all items were added to get the total GIS score; a higher score indicates a stronger generational identity. The GIS-12 demonstrated excellent reliability (McDonald's omega $=.89)$ and satisfactory temporal stability $(I C C$ $=.59,95 \% C I=0.27-0.77$ ) over a 4-week interval and convergent validity (Islam \& Haque, 2021).

\section{Transitional impact of war}

We used the 12-item Transitional Impact Scale (TIS, Svob et al., 2014) to assess the changes the independence war brought about to the participants' lives. TIS consists of two factors: material change and psychological change, each comprising six items. Each item was scored on a fivepoint Likert scale ranging from 1 (Completely Disagree) to 5 (Completely agree). Responses of six material change items and six psychological change items were averaged to get a material change score and a psychological change score, respectively. Following standard procedure, TIS was translated into Bangla (e.g., forward-backward translation and judged by an expert panel). We replaced the phrase "This event" with "War of independence" for each item, for example, "The war of independence has changed where I live" (material change) and "The war of independence has changed the way I think about things" (psychological change). The goodness of fit of the two-factor solution for the Bangla TIS-12 was checked using confirmatory factor analysis with maximum likelihood estimation $\left(\chi^{2}\right)$ $d f=272.83 / 53=5.15, C F I=0.92, T L I=0.90, R M S E A$ $=0.09$, and $S R M R=0.05$ ). The Bangla TIS also demonstrates excellent internal consistency (Cronbach's alpha for material change $=.86$ and psychological change $=.87$ ).

Table 1 The 12-item generational identity scale

1. It is important for my generation to pass along the experiences we have undergone.

2. I think my generation is meaningful to many people.

3. I feel that my generation will be remembered for a long time.

4. My generation has made unique contributions to society.

5. My generation can pass along valuable ideas and experiences.

6. I feel proud of my generation's achievements.

7. I feel good about my generation.

8 . I identify myself with my generation.

9. I see me as belonging to my generation.

10. I am a worthy member of the generation I belong to.

11. The generation I belong to is an important reflection of who I am.

12. I am a cooperative participant in the generation I belong to. 


\section{Procedure}

The project received approval from the Monash University Human Research Ethics Committee (ID: 11227). We recruited and trained 14 research assistants enrolled in Master's programmes in clinical/counselling and educational psychology at the University of Dhaka. Eligible participants were tested individually in their preferred locations, mostly at their residences. The survey questionnaires included separate sections for each measure mentioned above, along with a demographic information sheet to record the participants' sexual identity, socioeconomic status, education, birth date, and veteran identity (veteran/nonveteran). Participants were presented with an explanatory statement in which they were informed about the nature of the study, risks involved, and their rights. They were also informed that their participation was voluntary and that they could stop participation anytime they liked. When they agreed to participate and signed the written consent form, the data collection started. Where needed, the research assistants read out the items from the questionnaire and recorded their responses. The entire session, conducted in Bangla, took approximately half an hour.

\section{Coding of autobiographical memories and dating protocols}

For 476 participants, accounting three memories for each, a total of 1428 memories were expected. However, 11 memories were missing, giving a total of 1,417 memories with date estimates. Following a qualitative thematic analysis approach, we coded memory protocols to explore what constitutes an event memory (Braun \& Clarke, 2006). The content analysis revealed four recurrent thematic areas: (i) War and struggle: Memories that were centred on the 1971 liberation war and political activities; (ii) Childhood and schooling: Memories that were about participants' childhood and schooling events; (iii) Family and work: Memories that were about participants' family life and work; and (iv) Other: Memories that did not fall any of the above categories.

The dating protocols were coded into three major categories suggested by Brown and Lee (2010): public/historical, personal/generic, and pop/sports/weather. A public/ historical dating protocol was assigned when a memory was dated regarding the 1971 war or other collective events experienced by most people. A personal/generic dating protocol was assigned when memory is dated in reference to personally relevant information, such as school, people, places, work, and activities relevant to the participant's personal life. A pop/sports/weather dating protocol was assigned when a memory was dated in reference to popular cultural events, such as specific sporting events or weather. There were no unjustified dating protocols for this study, perhaps as each participant retrieved only three most important memories from their life. Table 2 presents examples of the dating protocols and memory category. The first author coded all the dating protocols and memory descriptions. A second coder blind to the study objectives coded randomly selected $30 \%$ of the total memories. The interrater reliability was found satisfactory (Kappa $=.73$, 95\% $C I=.64-.82$ ). Memory contents were further categorised for positive and negative valence. A separate coder blind to study objectives rated $20 \%(n=311)$ of the memory descriptions for positive and negative valence. The interrater agreement was satisfactory (Kappa $=.83$, $95 \% C I=.76-.89)$. Thus, the content-coding resulted in $638(45 \%)$ positive and $779(55 \%)$ negative memories.

Table 2 Examples of dating protocols and event memories

\begin{tabular}{|c|c|c|c|c|}
\hline Reported memory & Memory content category & Dating protocol & Dating protocol category & Memory valence \\
\hline $\begin{array}{l}\text { "I saw three dead bodies stuck } \\
\text { with submerged banana trees } \\
\text { during the flood." }\end{array}$ & War and struggle & $\begin{array}{l}\text { "The incident happened during the } \\
1971 \text { liberation war." }\end{array}$ & Public/ Historical & Negative \\
\hline $\begin{array}{l}\text { "One day, we blocked a train } \\
\text { carrying arms of the Pakistani } \\
\text { Military. This was one of the } \\
\text { great successes of our troop." }\end{array}$ & War and struggle & "During the liberation war." & Public/ Historical & Positive \\
\hline $\begin{array}{l}\text { "I started to work as a hawker on } \\
\text { the street at a very young age } \\
\text { due to poverty." }\end{array}$ & Family and work & $\begin{array}{l}\text { "When I was studying in high } \\
\text { school." }\end{array}$ & Personal/Generic & Negative \\
\hline $\begin{array}{l}\text { "My father gave me TK100 to join } \\
\text { a Boy Scout gathering in Lahore } \\
\text { (Pakistan)." }\end{array}$ & Childhood and schooling & "When I was in class 9." & Personal/Generic & Positive \\
\hline $\begin{array}{l}\text { "One day, I found a dead body in } \\
\text { my hotel." }\end{array}$ & Other & $\begin{array}{l}\text { "It was freezing then, perhaps in } \\
\text { December 1979." }\end{array}$ & Pop/Sports/weather & Negative \\
\hline
\end{tabular}




\section{Results}

\section{Living-in-history effect}

Out of 1,417 justified AMs, $32 \%(n=453)$ were dated in reference to public events, indicating a strong $\mathrm{LiH}$ effect. Further, a chi-square test of independence showed that participants' war identity (veteran vs. nonveteran) was associated with their use of dating references, $\chi^{2}(2,1417)=$ $66.25, p<.0001$, Cramer's V $=0.22$. The veterans $(58 \%)$ used overwhelmingly more public dating references than the nonveterans did (28\%) (Table 3). More than half of the total memories were family and work-related $(51.7 \%, n=$ 733). However, veterans recalled significantly more war and struggle $(40.4 \%, n=74)$ memories, whereas nonveterans recalled more family and work $(56.2 \%, n=664)$ memories, $\chi^{2}(3,1417)=40.99, p<.0001$, Cramer's V $=0.17$. Although memories with negative valence outnumbered those with positive valence, this pattern only held for nonveterans. Veterans retrieved more positive than negative memories. Veterans also reported higher perceived war impact $[t(474)=3.93, p<.0001, d=0.39)]$ and higher generational identity $[t(474)=6.68, p<.0001, d=0.91)]$ than their nonveteran counterparts (Table 3 ).
The temporal distribution of AMs revealed that both groups recalled an increased number of memories from 1969-1973, a period characterised by political struggles and the war of independence. Whereas the veterans retrieved $51.91 \%$ of their total memories, the nonveterans recalled $26.90 \%$ from this period. Participants primarily dated those memories coming from this period using public dating references. However, this pattern was more pronounced for veteran than nonveteran participants (Fig. 1). This result clearly indicates the robust effect of the Bangladesh independence war on the recall and dating of important AMs.

\section{Dating references and memory contents}

An examination of the memory contents revealed that public references were mostly used to date war and political struggle-related memories, while personal/generic references were mainly used to date non-war memories by both groups. Public references were used to date a smaller portion (20.3\%) of non-war personal memories (Fig. 2).

To specify the relations between memory content, memory valence, and use of public dating references, we ran a generalised linear mixed model (GLMM, Stroup, 2013). Since AMs are nested within individuals, participants were used as a random effect in the GLMM (Wright, 1998). Memory contents were collapsed into two major categories: war

Table 3 Descriptive statistics of the key measures for veteran and nonveteran participants

\begin{tabular}{|c|c|c|c|c|}
\hline Measure & Total & Veteran & Nonveteran & $\chi^{2 / t}$ \\
\hline Age (mean, SD) & $67.16(5.96)$ & $69.44(4.95)$ & $66.82(6.02)$ & $3.26 * *$ \\
\hline Age during War of Independence (mean, SD) & $18.98(5.94)$ & $21.27(4.95)$ & $18.64(6.01)$ & $3.28 * *$ \\
\hline \multicolumn{5}{|l|}{ Dating reference $(\%, \mathrm{n})$} \\
\hline Public/Historical & $32.0(453)$ & $57.9(106)$ & $28.1(347)$ & \multirow[t]{3}{*}{$66.25 * * *$} \\
\hline Personal/Generic & $65.5(928)$ & $39.3(72)$ & $69.4(856)$ & \\
\hline Pop/Sports/Weather & $2.5(36)$ & $2.7(5)$ & $2.5(31)$ & \\
\hline \multicolumn{5}{|l|}{ Memory category $(\%, \mathrm{n})$} \\
\hline War and struggle & $22.2(315)$ & $40.4(74)$ & $19.5(241)$ & \multirow[t]{4}{*}{$40.99 * * *$} \\
\hline Child and schooling & $10.8(153)$ & $8.2(15)$ & $11.2(138)$ & \\
\hline Family and work & $51.7(733)$ & $37.7(69)$ & $53.8(664)$ & \\
\hline Other & $15.2(216)$ & $13.7(25)$ & $15.5(191)$ & \\
\hline \multicolumn{5}{|l|}{ Memory valence $(\%, \mathrm{n})$} \\
\hline Positive & $45.0(638)$ & $53.6(98)$ & $43.8(540)$ & \multirow[t]{2}{*}{$6.17 *$} \\
\hline Negative & $55.0(779)$ & $46.4(85)$ & $56.2(694)$ & \\
\hline TIS (mean, SD) & $4.05(0.69)$ & $4.37(0.57)$ & $4.01(0.69)$ & $3.93 * * *$ \\
\hline Material change & $3.84(0.93)$ & $4.15(0.76)$ & $3.79(0.95)$ & $2.82 * *$ \\
\hline Psychological change & $4.27(0.62)$ & $4.59(0.45)$ & $4.22(0.62)$ & $5.72 * * *$ \\
\hline GIS (mean, SD) & $38.80(6.86)$ & $44.00(4.00)$ & $38.03(6.87)$ & $6.68 * * *$ \\
\hline Identification with the generation & $22.43(4.47)$ & $25.60(2.49)$ & $21.95(4.51)$ & $6.21 * * *$ \\
\hline Awareness of generational identity & $16.38(3.10)$ & $18.40(2.10)$ & $16.07(3.12)$ & $5.70 * * *$ \\
\hline
\end{tabular}

TIS Transitional Impact Scale, GIS Generational Identity Scale

$* p<.05, * * p<.01, * * * p<.0001$ 


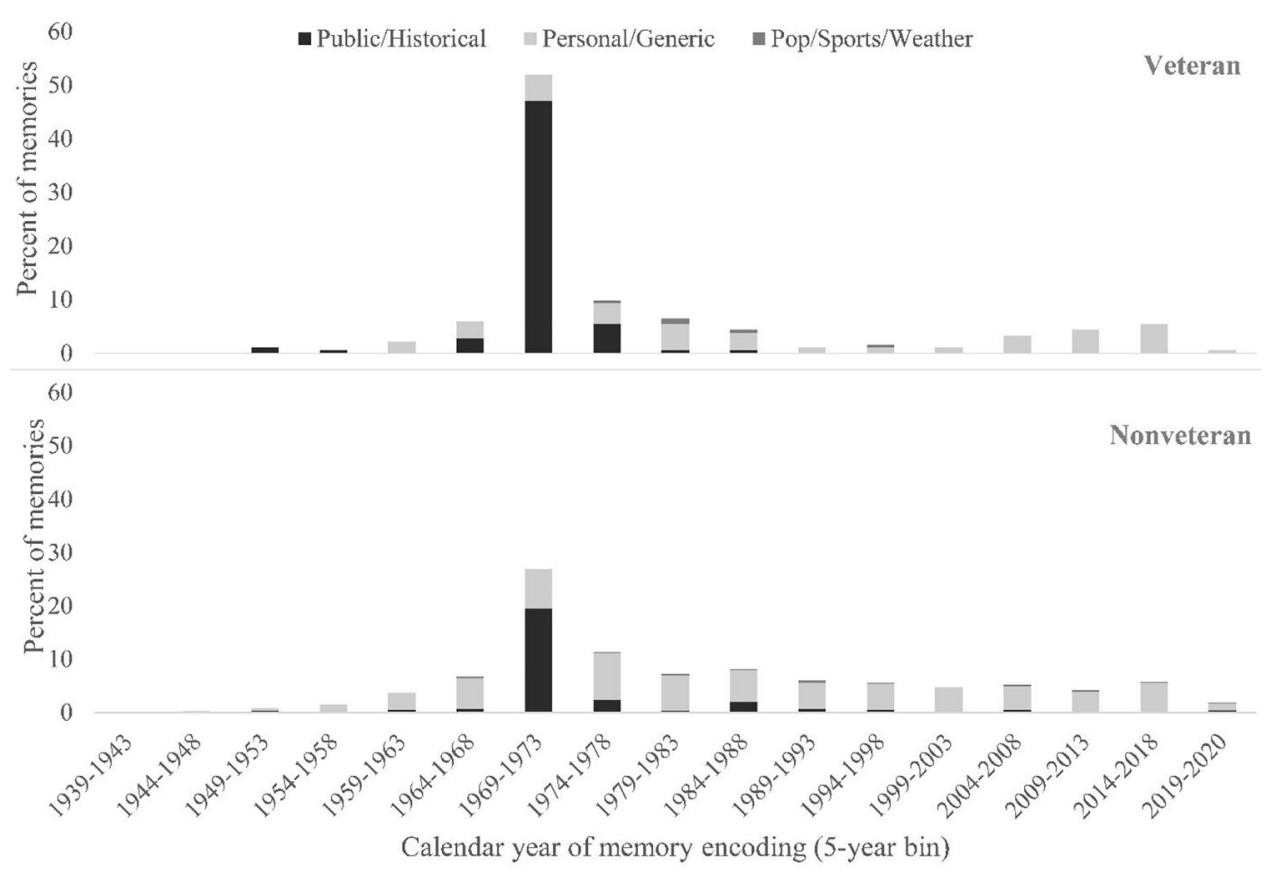

Fig. 1 Calendar year distribution of memories as a function of dating references stratified by veterans (upper panel) and nonveterans (lower panel)

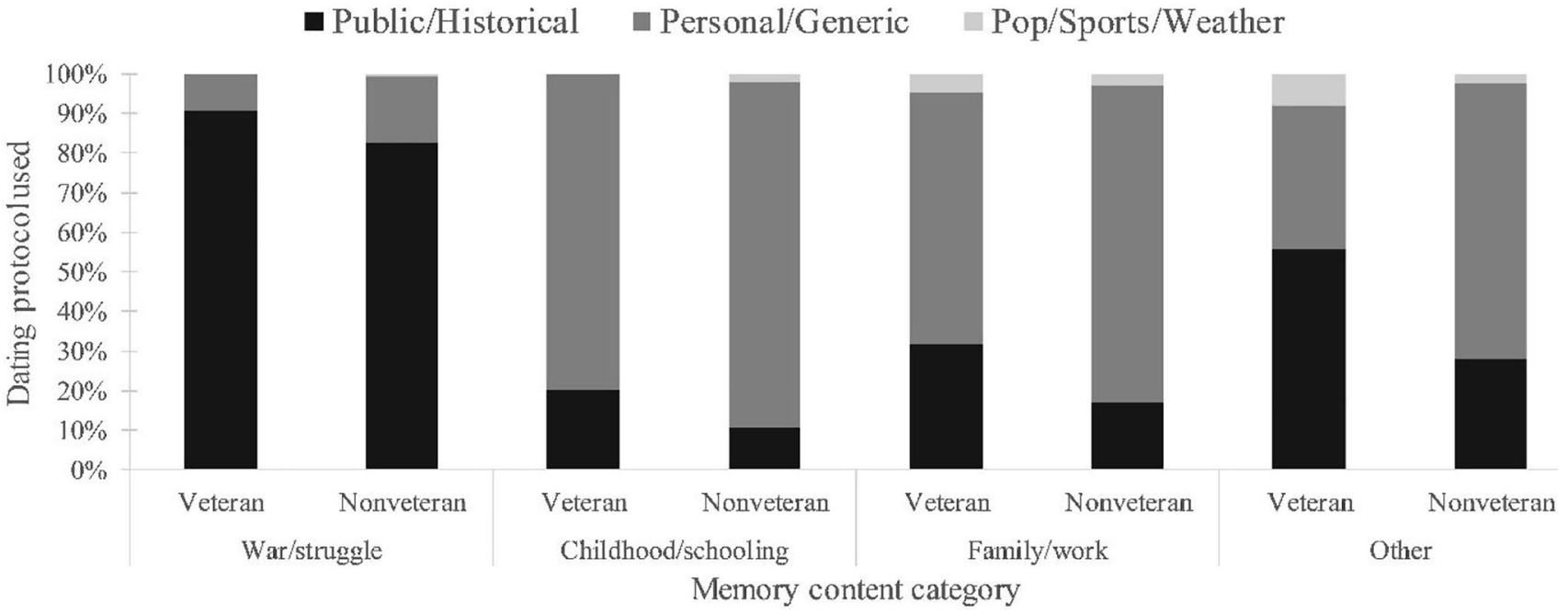

Fig. 2 Percentage of dating protocols used to date different memory categories by veterans and nonveterans

memory and non-war memory. A binary logit model with dating references (public vs. personal) as response category, memory content (war vs. non-war), and memory valence (positive vs. negative) as fixed effect predictors reveals that relative to non-war memories, the odds of war memories to be dated by public references was 36.74 (95\% CI $=25.18-53.61, t(1,1414)=18.71, p<.001)$. Compared to positive memories, the odds of negative memories to be dated by a public reference was $1.75(95 \% C I=1.27-2.41$, $t(1,1414)=3.43, p=.001)$.

\section{Individual differences in using public dating references}

To explore individual differences in using public references, we categorised the use of public dating references into four groups. The first group consists of participants who did not use a public reference to date memories. The second group used the public reference to date one memory, the third group used for two, and the fourth group used for all three memories. First, the four groups were not equal in number, 
$\chi^{2}(3,474)=123.01, p<.0001, w=0.51$, with nearly half of the participants $(45.36 \%, n=215)$ did not use any public references to date their memories. In other words, they used personal references. The number of participants decreases with the increased use of public references for memory dating. For example, 24.47\% ( $n=116)$ of the participants used a public reference to date for only one memory as opposed to $19.41 \%(n=92)$ and $10.76 \%(n=51)$ of the participants who used a public reference to date two and three memories, respectively. This pattern was maintained by nonveteran participants. In contrast, around $36 \%(n=22)$ of the veterans used public references to date two of their memories as opposed to around $23 \%(n=14)$ who used a public reference for one memory or $26 \%(n=16)$ who used for all three memories. Participants' age, scores of material and psychological changes due to war, and awareness of generational importance were also increased for participants with the increased use of public references (Table 4).

To ascertain each potential predictor's role in the use of public references, we conducted a multinomial logistic regression analysis. Specifically, we wanted to see relative to no use, which factors influence the likelihood of using public references for a one, two, or three memories. The model contained six predictors: veteran identity, participants' age, two TIS subscales (material change and psychological change), and two GIS subscales (identification with the generation and awareness of the generational importance). The full model containing all predictors was statistically significant, $\chi^{2}(18,476)=81.16, p<.0001$, indicating that the model distinguished between respondents who did and did not use a public reference. Participant's identity as a veteran significantly predicted the likelihood of using public dating references. The odds ratio indicates that as participant's identity changes from nonveteran to veteran, the change in the odds of using public reference for one memory compared to no use is 4.25 , for two memories compared to no use is 8.19 , and for three memories compared to no use is 9.67 after controlling for the effect of all other predictors. Age and material change were also found to be significant predictors of the likelihood of using public references for two or three memories relative to no use. For example, as the age increased by one year, the change in the odds of using public references for two memories relative to no use is 1.07 and for three memories relative to no use is 1.08 . Similarly, one unit increase of material change score is associated with the change in the odds of using public references for two memories relative to no use is 1.47 and for three memories relative to no use is 1.75 . Identification with the generation was significantly but inversely associated with the likelihood of using public references for one, two, and three memories relative to no use. One unit increase in identification with the generation score was associated with a change in the odds of using public reference for one memory relative no use is 0.93 , two memories relative to no use is 0.92 , and three memories relative to no use is 0.89 (Table 5).

\section{Discussion}

This is the first study investigating the $\mathrm{LiH}$ effect in the dating of autobiographical memories (AMs) through the important memory method. There were three specific research objectives. First, if Bangladeshi older adults show any $\mathrm{LiH}$ effect in dating AMs that were judged highly significant. The results revealed a clear $\mathrm{LiH}$ effect, and this effect has appeared stronger (32.0\%) than the effects observed in previous studies (see Online Supplementary Materal, Table 1). Typically, participants from war-affected regions tended to show an enhanced $\mathrm{LiH}$ effect. The current finding is in line with the results of studies conducted in war-affected regions

Table 4 Differences of demographic, transition impact, and generational identity by the level of public dating references used

\begin{tabular}{|c|c|c|c|c|c|}
\hline & \multicolumn{4}{|c|}{ Use of public references } & \multirow[t]{2}{*}{$\chi^{2} / F$} \\
\hline & Not used & Used for one memory & Used for two memories & $\begin{array}{l}\text { Used for three } \\
\text { memories }\end{array}$ & \\
\hline Total $(\%, \mathrm{n})$ & $45.36(215)$ & $24.47(116)$ & $19.41(92)$ & $10.76(51)$ & $123.01 * * *$ \\
\hline \multicolumn{6}{|l|}{ Identity $(\%, \mathrm{n})$} \\
\hline Veteran & $14.75(9)$ & $22.95(14)$ & $36.07(22)$ & $26.23(16)$ & $40.10 * * *$ \\
\hline Nonveteran & $49.88(206)$ & $24.70(102)$ & $16.95(70)$ & $8.47(35)$ & \\
\hline \multicolumn{6}{|c|}{ Continuous measures (Mean, SD) } \\
\hline Age & $66.02(5.29)$ & $67.33(6.03)$ & $68.63(6.75)$ & $68.90(6.14)$ & $6.16^{* * *}$ \\
\hline Material change & $3.74(1.04)$ & $3.76(0.82)$ & $3.96(0.82)$ & $4.17(0.81)$ & $3.72 *$ \\
\hline Psychological change & $4.25(0.65)$ & $4.18(0.58)$ & $4.32(0.57)$ & $4.47(0.59)$ & $2.95^{*}$ \\
\hline Identification with generation & $22.85(4.16)$ & $21.47(5.06)$ & $22.29(4.54)$ & $23.08(3.98)$ & $2.81 *$ \\
\hline Awareness of generation & $16.51(3.08)$ & $15.66(3.50)$ & $16.39(2.82)$ & $17.39(2.38)$ & $4.07 * *$ \\
\hline
\end{tabular}

${ }^{*} p<.05, * * p<.01, * * * p<.0001$ 
Table 5 Factors affecting the use of public references in dating single or multiple memories relative to no use

\begin{tabular}{|c|c|c|c|c|c|c|}
\hline \multirow{3}{*}{$\begin{array}{l}\text { Reference } \\
\text { Comparator }\end{array}$} & \multicolumn{6}{|l|}{ No use } \\
\hline & \multicolumn{2}{|c|}{ Used for one memory } & \multicolumn{2}{|c|}{ Used for two memories } & \multicolumn{2}{|c|}{ Used for three memories } \\
\hline & B & $\begin{array}{l}\text { OR } \\
(95 \% \mathrm{CI})\end{array}$ & B & $\begin{array}{l}\text { OR } \\
(95 \% \mathrm{CI})\end{array}$ & $\mathrm{B}$ & $\begin{array}{l}\text { OR } \\
(95 \% \mathrm{CI})\end{array}$ \\
\hline Veteran & $1.45 * * *$ & $\begin{array}{l}4.25 \\
(1.72,10.51)\end{array}$ & $2.10 * * *$ & $\begin{array}{l}8.19 \\
(3.43,19.56)\end{array}$ & $2.27 * * *$ & $\begin{array}{l}9.67 \\
(3.69,25.32)\end{array}$ \\
\hline Age & 0.04 & $\begin{array}{l}1.04 \\
(1.00,1.08)\end{array}$ & $0.07 * *$ & $\begin{array}{l}1.07 \\
(1.03,1.12)\end{array}$ & $0.08 * *$ & $\begin{array}{l}1.08 \\
(1.02,1.14)\end{array}$ \\
\hline Material change & 0.21 & $\begin{array}{l}1.23 \\
(0.91,1.66)\end{array}$ & $0.38 *$ & $\begin{array}{l}1.47 \\
(1.03,2.09)\end{array}$ & $0.56^{*}$ & $\begin{array}{l}1.75 \\
(1.08,2.84)\end{array}$ \\
\hline Psychological change & -0.12 & $\begin{array}{l}0.89 \\
(0.55,1.44)\end{array}$ & -0.05 & $\begin{array}{l}0.95 \\
(0.54,1.66)\end{array}$ & 0.02 & $\begin{array}{l}1.02 \\
(0.47,2.21)\end{array}$ \\
\hline Identification with generation & $-0.07 *$ & $\begin{array}{l}0.93 \\
(0.87,1.00)\end{array}$ & $-0.08^{*}$ & $\begin{array}{l}0.92 \\
(0.86,1.00)\end{array}$ & $-0.12^{*}$ & $\begin{array}{l}0.89 \\
(0.80,0.98)\end{array}$ \\
\hline Awareness of generation & -0.06 & $\begin{array}{l}0.94 \\
(0.85,1.04)\end{array}$ & -0.03 & $\begin{array}{l}0.97 \\
(0.86,1.09)\end{array}$ & 0.10 & $\begin{array}{l}1.11 \\
(0.93,1.31)\end{array}$ \\
\hline
\end{tabular}

Note. $R^{2}=0.157$ (Cox and Snell) and 0.171 (Nagelkerke). Model $\chi^{2}(18,476)=81.16, p<.0001$

$* p<.05, * * p<.01, * * * p<.0001$

in which the LiH effect ranged from $5 \%$ to $27 \%$ (Bohn \& Habermas, 2016; Brown \& Lee, 2010; Brown et al., 2009; Zebian \& Brown, 2014). However, one should be cautious about interpreting this result as we used the important memory method, whereas those early studies used the word-cue method.

While the word-cue method provides a neutral sample of memories from across the lifespan (Crovitz \& Schiffman, 1974), a request for the most important memories elicits events mostly from adolescence and early adulthood as many significant life events tend to occur during this period for a typical person (Berntsen \& Rubin, 2002; Rubin \& Berntsen, 2003). For the current sample, this critical period coincided with the two vital historical events - the 1960s Bengali nationalist movement and the 1971 Bangladesh War of Independence, which resulted in the integration of many personal memories with the major public memories. For example, a good number of our participants were freedom fighters who considered the "liberation war" as their most significant life event. Many others who fled the country and took shelter in a neighbouring country considered "escaping violence and atrocity" as their most significant memory. Whereas the liberation was typically rated as a positive event, being exposed to violence and atrocity was judged negative. Despite the opposite valence, both events spawned many memories considered highly significant. Previous studies showed that participants tended to provide higher importance ratings for the public events that happened during their critical developmental years (Schuman \& Corning, 2012; Schuman \& Scott, 1989; Taylor et al., 2017). As we cued our participants with the 'most important memory', the war played a vital role in navigating their personal memories.
We analysed the memory content as well as dating protocols to understand the dating preferences. We found that our participants overwhelmingly used public event references to date memories related to war and political struggle. Participants also used this kind of references to date some non-war personal memories $(20 \%)$. The results revealed that negative memories were associated with the increased use of public dating protocols (Brown, 2016). AMs for the current sample contained more negative than positive events $(55 \%$ vs. $45 \%$ ), and most were related to the war. Therefore, it is not surprising that public event references would mostly be used for negative memories. The degree of material changes in the individual brought about by the historical event was positively associated with the degree of LiH effect (Gu et al., 2017).

The second research objective was to see if veteran and nonveteran participants differed regarding the $\mathrm{LiH}$ effect. Surprisingly, we observed that the $\mathrm{LiH}$ effect was twice as stronger in the veteran than in nonveteran participants. To explain this result, we might consider two factors: the transitional impact of the war, which was stronger among the veterans than nonveterans. Second, the generational identity, which was also stronger among the veteran than nonveteran participants. The war has changed the fabric of daily life of the veterans more than the nonveterans, while at the same time, war has also given a stronger generational identity to the veterans than nonveterans. Veterans as a generational group see the independence war as central to their life experiences, which has given them a new collective identity (Conway \& Haque, 1999). To attain this identity, which is a Bengali identity as opposed to their previous Pakistani identity, they sacrificed the most. They left their homes, joined 
the war, and risked their lives to materialize a shared dream - to free their country to promote freedom, equality, and human rights (Rahman, 1982). Hence, whatever happened during the war was integrated with their life narratives, so they frequently referred to the war while sharing their important memories.

Although veterans and nonveterans reported a higher proportion of memories from 1969 to 1973, they were markedly different in their recollections - veterans reported $51.91 \%$, and nonveterans reported $26.90 \%$ of their memories. The preferential recall of AMs from this period deserves careful interpretation. This is the period when several important political events took place in then East Pakistan. The year 1969 witnessed a popular uprising against the military dictators who ruled the country for over a decade. This mass movement ended up with the fall of the military regime with power transfer to another army General who promised to organise a nationwide general election and hand over power to the elected representatives. As promised, general elections were organised in 1970 in which the Bengali nationalist party Awami League led by Sheikh Mujibur Rahman won the majority of the seats in the parliament. However, the Military did not hand over power to the League, which caused a massive nationwide protest and agitation. The Army suddenly launched a major crackdown operation, called 'Operation Search Light', on the night of 25 March 1971 to diminish the voice of the East Pakistani/Bengali people. The people of East Pakistan declared independence on 26 March 1971, which escalated the war. After 9 months of bloody war, the Pakistani Army surrendered, culminating in creating an independent Bangladesh (Rahman, 1982). In 1972, Bangladesh wrote its first constitution, and in 1973, fresh general elections were held in which the Awami League won the landslide victory once again and formed the government. With the formation of an elected government, the life of the millions of Bengali people became relatively stable. Hence, we can assert that the years 1969-1973 are a transition period through which the Bangladeshi people attained a new national identity. Preferential recollection of memories from this period is due to the availability of numerous selfrelevant memories that became integrated with the participants' personal narratives (Islam et al., 2021). The period also coincided with the timing of identity formation as most of our participants $(81.72 \%)$ were in their adolescence and early adulthood during 1969-1973, thus intensifying their memory recollection (Conway et al., 2005; Rubin \& Schulkind, 1997; Rubin et al., 1986).

The third objective was to see what factors significantly predicted the usage of H-DAPs while dating AMs. The results showed that veteran identity emerged as a significant predictor after controlling for the transitional effect (material change due to war). We suggest that two different factors have been operating during veterans' memory recall - one related to encoding and another to retrieval. First, veterans encoded war memories better than nonveterans because those memories were personally significant and defined who they are (Conway \& Pleydell-Pearce, 2000; Islam et al., 2021). Second, veterans' increased use of H-DAPs is perhaps due to their current veteran identity $-\mathrm{a}$ factor that operates at the retrieval level. Their recollections have been intensified by the self-reference effect, a tendency to recall information better that is encoded about the self (Rogers et al., 1977). However, we recommend that future studies confirm this prediction by employing appropriate identity measures. A tool to measure the magnitude of identification with the war would be useful in this regard.

\section{Conclusion}

Older Bangladeshi adults, who witnessed the 1960s Bengali nationalist movement and 1971 war of independence, showed a strong $\mathrm{LiH}$ effect in dating their most important memories. However, this effect was different across the war veteran and nonveteran participants - veterans showing stronger effect than their nonveteran counterparts. Unlike earlier studies on the LiH effect, we examined memory content and dating protocols, showing a significant association between dating references and the elevated $\mathrm{LiH}$ effect among veterans. While some primary results (e.g., using war references to date some non-war personal memories and the increased use of public event references for negative memories) confirmed the predictions of the transition theory, the higher-order findings (e.g., enhanced $\mathrm{LiH}$ effects in veterans than nonveterans) were likely to be better explained by the identity-based accounts.

Supplementary Information The online version contains supplementary material available at https://doi.org/10.3758/s13421-021-01250-6.

Acknowledgements The authors thank all three funding organisations for their support. The authors also acknowledge the contribution of older participants and critical feedback supplied by the three anonymous reviewers.

Availability of data and materials The datasets generated during and/or analysed during the current study are available in the Monash repository Bridges. Weblink: https://doi.org/10.26180/13489923

Authors' contributions Both authors designed the study, AI conducted the field study, processed and analysed the data, and drafted the manuscript. SH edited and improved the scientific quality of the manuscript. Both authors reviewed and approved the final manuscript.

Funding Azharul Islam is supported by the University of Dhaka, Bangladesh, with a paid study leave. Monash University Malaysia offered a Merit Scholarship for Ph.D. to Azharul Islam. A Global Asia 21 Research Platform Grant (GA/CV-16-L01) supported data collection for this study. 


\section{Declarations}

\section{Conflicts of interest/Competing interests None}

Ethics approval Ethical approval was obtained from the Monash University Human Ethics Committee (Project number: 11227). The procedures used in this study adhere to the tenets of the Declaration of Helsinki.

Consent to participate Written informed consent was obtained from all individual participants included in the study

Consent for publication Participants gave written consent to publish their data

Code availability Not applicable

\section{References}

Berntsen, D., \& Rubin, D. C. (2002). Emotionally charged autobiographical memories across the life span: The recall of happy, sad, traumatic and involuntary memories. Psychology and Aging, 17(4), 636-652. https://doi.org/10.1037//0882-7974.17.4.636

Bohn, A., \& Habermas, T. (2016). Living in history and living by the cultural life script: How older Germans date their autobiographical memories. Memory, 24(4), 482-495. https://doi.org/10.1080/ 09658211.2015 .1019890

Braun, V., \& Clarke, V. (2006). Using thematic analysis in psychology. Qualitative Research in Psychology, 3(2), 77-101. https://doi.org/ 10.1191/1478088706qp063oa

Brown, N., Schweickart, O., \& Svob, C. (2016). The effect of collective transitions on the organization and contents of autobiographical memory: A transition theory perspective. The American Journal of Psychology, 129(3), 259. https://doi.org/10.5406/amerjpsyc. 129.3.0259

Brown, N. R. (1990). Organization of public events in long-term memory. Journal of Experimental Psychology: General, 119(3), 297. https://doi.org/10.1037/0096-3445.119.3.297

Brown, N. R. (2016). Transition theory: A minimalist perspective on the organization of autobiographical memory. Journal Appl. Res. Mem. Cogn., 5(2), 128-134. https://doi.org/10.1016/j.jarmac. 2016.03.005

Brown, N. R., Hansen, T. G. B., Lee, P. J., Vanderveen, S. A., \& Conrad, F. G. (2012). Historically defined autobiographical periods: Their origins and implications. In D. C. Rubin \& D. Berntsen (Eds.), Understanding autobiographical memory: Theories and approaches (pp. 160-180). Cambridge University Press. https:// doi.org/10.1017/CBO9781139021937.013

Brown, N. R., \& Lee, P. J. (2010). Public events and the organization of autobiographical memory: An overview of the living-in-history project. Behavioral Sciences of Terrorism and Political Aggression, 2(2), 133-149. https://doi.org/10.1080/19434471003597431

Brown, N. R., Lee, P. J., Krslak, M., Conrad, F. G., Hansen, T. G., Havelka, J., \& Reddon, J. R. (2009). Living in history: How war, terrorism, and natural disaster affect the organization of autobiographical memory. Psychological Science, 20(4), 399-405. https://doi.org/10.1111/j.1467-9280.2009.02307.x

Camia, C., Menzel, C., \& Bohn, A. (2019). A positive living-in-history effect: The case of the fall of the berlin wall. Memory, 27(10), 1381-1389. https://doi.org/10.1080/09658211.2019.1661494

Conway, M. A. (2005). Memory and the self. Journal of Memory and Language, 53(4), 594-628. https://doi.org/10.1016/j.jml.2005.08. 005
Conway, M. A., \& Haque, S. (1999). Overshadowing the reminiscence bump: Memories of a struggle for independence. Journal of Adult Development, 6(1), 35-44. https://doi.org/10.1023/A: 1021672208155

Conway, M. A., Justice, L. V., \& D'Argembeau, A. (2019). The selfmemory system revisited: Past, present, and future. In J. H. Mace (Ed.), The organization and structure of autobiographical memory (First ed., pp. 28-51). OUP Oxford.

Conway, M. A., \& Pleydell-Pearce, C. W. (2000). The construction of autobiographical memories in the self-memory system. Psychological Review, 107(2), 261-288. https://doi.org/10.1037/ 0033-295X.107.2.261

Conway, M. A., Singer, J. A., \& Tagini, A. (2004). The self and autobiographical memory: Correspondence and coherence. Social Cognition, 22(5: Special issue), 491-529. https://doi.org/10. 1521/soco.22.5.491.50768

Conway, M. A., Wang, Q., Hanyu, K., \& Haque, S. (2005). A crosscultural investigation of autobiographical memory. Journal of Cross-Cultural Psychology, 36(6), 739-749. https://doi.org/10. 1177/0022022105280512

Crovitz, H. F., \& Schiffman, H. (1974). Frequency of episodic memories as a function of their age. Bulletin of the Psychonomic Society, 4(5), 517-518. https://doi.org/10.3758/BF03334277

Dragojević, M. (2013). Memory and identity: Inter-generational narratives of violence among refugees in Serbia. Nationalities Papers, 41(6), 1065-1082. https://doi.org/10.1080/00905992. 2013.801415

Ernst, A., \& Rathbone, C. J. (2019). The role of the self in the organization of memories and imagined future events. In J. H. Mace (Ed.), The organization and structure of autobiographical memory (pp. 134-159). OUP Oxford.

Friedman, W. J. (1993). Memory for the time of past events. Psychological Bulletin, 113(1), 44-66. https://doi.org/10.1037/00332909.113.1.44

Gu, X., Tse, C. S., \& Brown, N. R. (2017). The effects of collective and personal transitions on the organization and contents of autobiographical memory in older Chinese adults. Mem Cognit, 45(8), 1335-1349. https://doi.org/10.3758/s13421-017-0733-0

Holmes, A., \& Conway, M. A. (1999). Generation identity and the reminiscence bump: Memory for public and private events. Journal of Adult Development, 6(1), 21-34. https://doi.org/10.1023/A: 1021620224085

Islam, A., \& Haque, S. (2021). Construction and validation of a generational identity scale on Bangladeshi older adults. Frontiers in Psychology, 12, Article 703237. https://doi.org/10.3389/fpsyg. 2021.703237

Islam, A., Sheppard, E., Conway, M. A., \& Haque, S. (2021). Autobiographical memory of war veterans: A mixed-studies systematic review. Memory Studies, 14(2), 214-239. https://doi.org/10.1177/ 1750698019863152

Koppel, J., \& Berntsen, D. (2019). The cue-dependency of the "reminiscence bumps" in autobiographical memory and memory for public events: What they reveal about memory organization. In J. $\mathrm{H}$. Mace (Ed.), The organization and structure of autobiographical memory (pp. 160-182). OUP Oxford.

Mannheim, K. (1952). The problems of generations. In K. Mannheim (Ed.), Essays on the sociology of knowledge (pp. 276-321). London : Routledge \& Kegan Paul.

Nourkova, V. V., \& Brown, N. R. (2015). Assessing the impact of "the collapse" on the organization and content of autobiographical memory in the former soviet union. Journal of Social Issues, 71(2), 324-337. https://doi.org/10.1111/josi.12113

Pfeiffer, E. (1975). A short portable mental status questionnaire for the assessment of organic brain deficit in elderly patients. Journal of the American Geriatrics Society, 23(10), 433-441. https://doi.org/ 10.1111/j.1532-5415.1975.tb00927.x 
Rahman, H. H. (1982). History of Bangladesh war of independence: Documents (Vol. 1-15). Ministry of Information, Government of the Peoples' Republic of Bangladesh.

Roccaforte, W. H., Burke, W. J., Bayer, B. L., \& Wengel, S. P. (1994). Reliability and validity of the short portable mental status questionnaire administered by telephone. Journal of Geriatric Psychiatry and Neurology, 7(1), 33-38. https://doi.org/10.1177/08919 8879400700107

Rogers, T. B., Kuiper, N. A., \& Kirker, W. S. (1977). Self-reference and the encoding of personal information. Journal of Personality and Social Psychology, 35(9), 677. https://doi.org/10.1037/ 0022-3514.35.9.677

Rubin, D. C., \& Berntsen, D. (2003). Life scripts help to maintain autobiographical memories of highly positive, but not highly negative, events. Memory \& Cognition, 31(1), 1-14. https://doi. org/10.3758/BF03196077

Rubin, D. C., \& Schulkind, M. D. (1997). The distribution of autobiographical memories across the lifespan. Memory \& Cognition, 25(6), 859-866. https://doi.org/10.3758/BF03211330

Rubin, D. C., Wetzler, S. E., \& Nebes, R. D. (1986). Autobiographical memory across the lifespan. In Autobiographical memory. (pp. 202-221). Cambridge University Press. https://doi.org/10.1017/ CBO9780511558313.018

Schuman, H., \& Corning, A. (2012). Generational memory and the critical period: Evidence for national and world events. Public Opinion Quarterly, 76(1), 1-31. https://doi.org/10.1093/poq/ nfr037

Schuman, H., \& Scott, J. (1989). Generations and collective memories. American Sociological Review, 54(3), 359-381. https://doi.org/ $10.2307 / 2095611$

Shi, L., \& Brown, N. (2016). The effect of immigration on the contents and organization of autobiographical memory: A transition-theory perspective. Journal Applied Research in Memory and Cognition, 5(2), 135-142. https://doi.org/10.1016/j.jarmac.2016.03.002
Shum, M. S. (1998). The role of temporal landmarks in autobiographical memory processes. Psychological Bulletin, 124(3), 423. https://doi.org/10.1037/0033-2909.124.3.423

Stroup, W. W. (2013). Generalized linear mixed models : Modern concepts, methods and applications., New York : CRC Press.

Svob, C., Brown, N. R., Reddon, J. R., Uzer, T., \& Lee, P. J. (2014). The transitional impact scale: Assessing the material and psychological impact of life transitions. Behav Research Methods, 46(2), 448-455. https://doi.org/10.3758/s13428-013-0378-2

Taylor, R. J., Burton-Wood, C. G., \& Garry, M. (2017). America was great when nationally relevant events occurred and when Americans were young [Article]. Journal of Applied Research in Memory and Cognition, 6(4), 425-433. https://doi.org/10.1016/j. jarmac.2017.05.003

Thompson, C. P., Skowronski, J. J., Larsen, S. F., \& Betz, A. (1996). Autobiographical memory: Remembering what and remembering when. Lawrence Erlbaum Associates, Inc.

Wright, D. B. (1998). Modelling clustered data in autobiographical memory research: The multilevel approach. Applied Cognitive Psychology, 12(4), 339-357. https://doi.org/10.1002/(SICI)10990720(199808)12:4<339::AID-ACP571>3.0.CO2-D

Zebian, S., \& Brown, N. R. (2014). Living in history in Lebanon: The influence of chronic social upheaval on the organisation of autobiographical memories. Memory, 22(3), 194-211. https://doi.org/ $10.1080 / 09658211.2013 .775310$

Publisher's note Springer Nature remains neutral with regard to jurisdictional claims in published maps and institutional affiliations. 